\title{
The Effects of Loneliness and Internalized Stigma on Perceived Social Support in People with AIDS: A Cross-Sectional Study
}

\author{
Eleni Tsilika \\ Efi Parpa \\ Pain Relief and Palliative Care Unit \\ Dept. of Radiology \\ Areteion Hospital \\ National \& Kapodistrian University of Athens \\ School of Medicine \\ Greece \\ Polyxeni Pikea \\ OKANA Anti-Drug Center \\ Greece \\ Stylianos Katsaragakis \\ Department of Nursing \\ Faculty of Human Movement and Quality of Life \\ University of Peloponnese \\ Sparta \\ Kyriaki Mystakidou \\ Pain Relief and Palliative Care Unit \\ Dept. of Radiology \\ Areteion Hospital \\ National \& Kapodistrian University of Athens \\ School of Medicine \\ Greece
}

\begin{abstract}
A cross-sectional study examined social support, loneliness, internalized stigma, the effects of loneliness and internalized stigma on perceived social support in 140 Greek adults with AIDS. The Medical Outcomes Study Social Support Scale, UCLA Loneliness Scale, and Internalized AIDS-Related Stigma were administered. Significant associations: between social support, social loneliness, psychological loneliness, isolation, and Aids Related Stigma. Psychological loneliness and isolation had the strongest effect on social support. Efforts reducing them may positively affect social support.
\end{abstract}

Keywords: AIDS, Greece, internalized stigma, loneliness, social support

\section{Introduction}

According to the United Nations Programme on HIV/AIDS nearly 21 million patients are now on antiretroviral treatment, boosting their life expectancy (United Nations Programme on HIV/AIDS [UNAIDS, 2017]; World Health Organization: Data and statistics), by mid-2017, while in 20161.0 million AIDS-related deaths were recorded (UNAIDS, 2017). In Greece, by nearly the end of 2017, 16,527 cases of HIV infection have been registered, 4,083 were AIDS cases and 9,500 were receiving antiretroviral therapy, while there were 2,746 deaths. New HIV diagnoses per 100,000 for the same time period have been reduced compared to previous years (Hellenic Center for Disease Control \& Prevention [HCDCP, 2017]). 
Nowadays, AIDS, is considered a chronic and in many cases manageable disease (Mills et al., 2011), consisting of physical-psychosocial problems (Mo \& Coulson, 2013), and an increased need for social support (Ware, Wyatt, \& Tugenberg, 2006). Nevertheless, many people complain about unfulfilled needs, and inadequate social support (Heckman, 2003). HIV/AIDS continues to unequally affect stigmatized populations (eg, homosexuals and those who inject drugs).

In Greece, since the 1990s, HIV/AIDS units have been operating within the national health system departments for the treatment of both HIV carriers and patients with AIDS. There are 17 HIV units operating and staffed by medical doctors, clinicians, nurses and administrative staff. Over the last 5 years there has been a reduction of HIV/AIDS new cases, reflecting the duplication of the outset of antiretroviral therapy (HCDCP E-bulletin).

People with AIDS satisfied with the actual support received, have less psychological distress, and higher selfesteem (Van Dam et al., 2005). It can be assessed both as the perceived assistance available, but also, as the actual support received. Social support includes: professional, peers, and family members (Orrick, Worrall, Morris, \& Wang, 2011), while the types of social support are: emotional, instrumental, information/education, and appraisal (Li, Sung-Jae, Panithee, Chuleeporn, \& Rotheram-Borus, 2009).

Additionally, people with AIDS often face stigma, prejudice, and discrimination, affecting access to testing, care, treatment (Mahajan et al., 2008), adherence (Grov, Golub, Parsons, Brennan, \& Karpiak, 2010), and access to social support systems (Baker, 1999) due to concealment of their seropositivity, fear of rejection, disease progression, and side-effects (Bogart et al., 2007). Earnshaw and Chaudior (2009) suggested that stigma includes enacted, anticipated, and internalized stigma. In particular, internalized stigma (assessed in the present study) has been argued that makes them feel shame, and guilt as they are worried about spreading infection to others (Lee, Kochman, \& Sikkema, 2002), thus feeling that they deserve received misbehavior. Despite progress in clinical care, stigma negative influences quality of life, while associated with loneliness (Herrmann et al., 2013).

It is a common psychological symptom of people with AIDS (Nokes \& Kendrew, 2001), affecting their everyday life, in that they expect and fear negative interactions, often recall negative social information, thus, resulting in withdrawal (Cacioppo, Hawkley, Norman, \& Berntson, 2011).

Although there are studies on the relationships between loneliness, isolation and social support (Acton, 2011; Coyle \& Dugan, 2012; Kuper, Marmot, \& Hemingway, 2002; Nicole et al., 2016; Udell et al., 2012), there are no studies addressing the possible effect of loneliness and internalized stigma on perceived social support in patient population, especially in people with AIDS.

In spite of great advances in the application of available resources for AIDS, perceptive of stigma, lonelinessisolation, and low social support still persist, while data in Greek patients is insufficient. The hypothesis under study is that loneliness and internalized stigma effect perceived social support in this population.

\section{Methods}

A cross-sectional design study was conducted in the Red Cross General Hospital "Special Infection Unit" in Athens, Greece, between December 2013 to August 2014. The study's inclusion criteria were: patients with AIDS, fluency in Greek language, while the exclusion criterion was <18 years old. From the 600 patients treated in the Unit, the study sample consisted of 154 consecutive and eligible people with AIDS treated in the Unit. Fourteen patients $(9.09 \%)$ refused to participate, so the final sample consisted of $140(90.90 \%)$ patients; 121 $(86.4 \%)$ were males, and the majority $(69 \%)$ was in the age group of 20-69 years old, single (61.4\%), living alone $(53.6 \%)$, and with high school education $(40.7 \%)$. No missing data were reported. Participants were informed of the study's nature and signed a written informed consent. The instruments: Medical Outcomes Study Social Support Survey, UCLA Loneliness Scale (Version 3), and Aids Related Stigma were completed, in the presence of a psychotherapist, who also recorded disease status, treatment and socio demographic characteristics (table 1). If needed, patients received additional information and/or clarifications. The hospital's ethics committee approved the study, conducted according to Declaration of Helsinki Principles and to guidelines for Good Clinical Practice. 
Table 1 Demographic Characteristics

\begin{tabular}{|l|l|l|r|}
\hline & & $N$ & \multicolumn{1}{|c|}{} \\
\hline \multirow{4}{*}{ Gender } & male & 121 & 86.4 \\
\cline { 2 - 4 } & female & 19 & 13.6 \\
\hline \multirow{5}{*}{ Education } & Single & 86 & 61.4 \\
\cline { 2 - 4 } & relation & 54 & 38.6 \\
\cline { 2 - 4 } & & & \\
\hline \multirow{5}{*}{ Occupation } & Junior High School & 19 & 13.6 \\
\cline { 2 - 4 } & High School & 57 & 40.7 \\
\cline { 2 - 4 } & University & 44 & 31.4 \\
\cline { 2 - 4 } & MSc-Phd & 20 & 14.3 \\
\hline Income & Retired & 22 & 15.7 \\
\cline { 2 - 4 } & Freelance & 19 & 13.6 \\
\cline { 2 - 4 } & Civil servant-Private official & 54 & 38.6 \\
\cline { 2 - 4 } & Unemployed & 45 & 32.1 \\
\hline Country of Origin & $<500 €$ & 45 & 32.1 \\
\cline { 2 - 4 } & $500-1.500 €$ & 83 & 59.3 \\
\cline { 2 - 4 } & $>1.500 €$ & 12 & 8.6 \\
\hline Age: mean \pm Sd (min-max) & Greece & 126 & 90.0 \\
\hline HIV duration: mean \pm Sd (min-max) & Other & 14 & 10.0 \\
\hline Treatment duration:median(min-max) & $43.10 \pm 11.96(20-69)$ & 20 & 69 \\
\hline
\end{tabular}

\subsection{Measures}

The Medical Outcomes Study Social Support Survey (MOS) is a self- administered, 19 items unidimensional, social support inventory, a five-point Likert scale (Hays, Sherbourne, \& Mazel, 1995). It consists of four functional support scales and an overall functional support index (Sherbourne, 1991). In the current study the Greek version of MOS (cronbach alpha $=.97$ ) was used (Parpa et al., 2016).

The UCLA Loneliness Scale (Version 3) is a 20-item scale measuring the subjective feeling of loneliness (Russel, 1996). For each question, there is a 4 - point scale, while scores range from 20-80. It is a unidimensional, valid and reliable instrument ( $\alpha=.89$ to .97 and $r=.73$ ). The Greek version of UCLA Loneliness scale was utilized (Pikea, Parpa, Tsilika, Galanos, \& Mystakidou, 2016). It consists three factors: social loneliness (items 2, 3, 4, 7 , 8, 11, 12, 14, 18), psychological loneliness (items 13, 15, 16, 19, 20), and isolation (items 1, 5, 6, 9, 10). The Internalized AIDS-Related Stigma Scale contains six-items. It represents self-effacing sentiments and adverse perspectives of people with HIV/AIDS. Each item has a yes/no response, summing up to a total score. The scale is internally consistent (overall $\alpha$ coefficient $=0.75)$ and time stable $(r=0.53)$ (Kalichman et al., 2009).

\subsection{Translation}

By using the "forward-backward" procedure the Internalized AIDS-Related Stigma Scale was translated from English to Greek. Then, two independent translators translated it to Greek, while another two translated it back to English. The final step was the matching of these translations.

\section{Statistical analyses}

Data was expressed as mean $\pm S . D$ for quantitative variables, and as percentages for qualitative variables. The Kolmogorov-Smirnov test was utilized for normality analysis of the quantitative variables. Bivariate analyses were carried out by the Student t-test, one-way ANOVA and Pearson's correlation coefficients, to assess the relation among MOS total score and the quantitative, qualitative demographic and clinical attributes. All demographic, clinical variables and questionnaires' total scores were presented ( $p$-value<.2) in bivariate analyses were incorporated in multiple linear regression, using the stepwise method to emerge at the final model and opt the most significant factors associated with MOS. All assumptions of linear regression analysis were examined. All tests were two-sided, while a $p$-value of <.05 was used for statistical significance. Analyses were conducted using the SPSS vr 17.00 statistical package. 


\subsection{Results}

\subsubsection{Descriptive}

The mean $( \pm s d)$ of MOS scale, UCLA scales, as well as MOS-total are presented in table 2. The average total score on MOS-total was 3.46 \pm 1.09 (range: 1.05-5.00) and for Aids-Related Stigma was 2.74 \pm 1.47 (range: 0-6). All UCLA scales mean scores were relatively high (table 2).

Table 2 Questionnaires’ Descriptive Statistics

\begin{tabular}{|l|c|c|l|c|}
\hline & $M$ & $S D$ & Min & Max \\
\hline Social Loneliness & 20.08 & 6.01 & 9.00 & 35.00 \\
\hline Psychological Loneliness & 10.66 & 3.69 & 5.00 & 20.00 \\
\hline Isolation & 9.24 & 3.01 & 5.00 & 16.00 \\
\hline Aids Related Stigma total & 2.74 & 1.47 & 0.00 & 6.00 \\
\hline MOS Scale & 3.46 & 1.09 & 1.05 & 5.00 \\
\hline
\end{tabular}

\subsubsection{Univariate Analyses}

MOS total had a highly negative correlation with social loneliness $(r=-.524, \mathrm{p}<0.005)$, psychological loneliness $(r=-.671, p<.005)$, isolation ( $r=-.357, p<.005)$, and Aids- related stigma ( $r=-.217, p<.05)$ (table not shown). However, there were no statistically significant associations between MOS total and the assessed qualitative variables (table not shown).

\subsubsection{Multivariate analyses}

Multiple regression analysis (stepwise model) examined the contribution of demographic and clinical variables as well as loneliness and stigma to participants' perceived social support. Examination of the strongest contributors to social support showed increased values of psychological loneliness (Beta coefficient \pm SE:-.167 $\pm .24 ; p<.0005$ ), isolation (Beta coefficient \pm SE: $-.030 \pm .015 ; p=.042$ ) and age (Beta coefficient \pm SE: -.010 $\pm .006 ; p=.077$ marginally) were associated with lower values of perceived social support (table 3).

Table 3 Multiple Regression Analysis of MOS Scale (Stepwise Method)

\begin{tabular}{|l|l|l|l|}
\hline & Beta coefficient & $S E$ & $p$ \\
\hline Constant & 6.288 & .354 & $<.001$ \\
\hline Psychological Loneliness & -.167 & .024 & $<.001$ \\
\hline Isolation & -.030 & .015 & .042 \\
\hline Age & -.010 & .006 & .077 \\
\hline
\end{tabular}

\section{Discussion}

By the end of October 2014 (the present study period concluded in August 2014), the total number of registered HIV infections in Greece was 14,288 (82.3\% men). Of these, 3638 had been diagnosed with AIDS. Approximately $6850 \mathrm{HIV}$-infected people are receiving antiretroviral treatment. The cumulative number of deaths was 2471. HIV reports during the first 10 months of 2014 are less than the same period in 2011-2013. Between Jan-Oct 2013, the number of HIV reports was 7.2 per 100,000 population while in 2014, the reporting rate dropped to 5.9. The newly reported HIV diagnoses in 2014 were 654 ( $86.1 \%$ males).

Although social support has a moderating effect on stressful life events (Komatsu et al. 2010), perceived social support appears as the most important as it advances self-esteem, resulting in a positive outcome in psychological health (Li, Sung-Jae, Panithee, Chuleeporn, \& Rotheram-Borus, 2009). For people with AIDS social relationships might be limited resulting in loneliness and isolation (Perlman \& Peplau, 1981), while most are, in some extent, stigmatized (Brouard \& Wills).

The study assesses, for the first time, the effects of loneliness and internalized stigma in their perception of social support. Consistent with previous studies, perceived social support had a significant correlation with loneliness (Sun et al., 2009). Loneliness may restrict people's capacity or obtain to social relationship. Thus, if they are better supported, their negative psychosocial repercussions might be blocked or diminished. Perceived social support also had a statistically significant correlation with "internalized stigma". 
This relationship has been acknowledged by other researchers (Kalichman et al., 2009), suggesting that diminished social support is linked to increased internalized stigma in people with AIDS. Accordingly, Li et al. (2009) reported that lower social support was significantly associated with higher stigma.

More importantly, multivariate analysis showed that psychological loneliness and isolation emerged as having a significant and independent effect on perceived social support. Higher rates of psychological loneliness and isolation might place people with AIDS at increased risk for poor social support. Interestingly, although social loneliness and internalized stigma had also strong bivariate correlations with social support, multiple regression analyses showed that they were not critical and decisive in predicting social support.

Age had a slight (trend) effect, which is consistent with existing research arguing that, whereas older individuals count on family members throughout illness, older AIDS individuals face several obstacles experiencing emotional and instrumental social support, while individuals aged 50 years and older are more socially isolated (Cantor \& Brennan, 2000).

The potency of the study comprises the use of a large indicative sample from a unique and important population, and the absence of missing data. On the other hand, a restriction is that it is difficult to speculate from a crosssectional study.

The present results highlight the importance of focusing counseling to reduce psychological loneliness and isolation to improve social support among people with AIDS. Moreover, by addressing them (i.e. loneliness and social isolation) through counseling may have an important role and benefits for the delivery of more tailored interventions for people with AIDS.

"This research received no specific grant from any funding agency in the public, commercial, or not-for-profit sectors." "The Author(s) declare(s) that there is no conflict of interest".

\section{References}

Acton, Q. A. (2011). Issues in Family and Geriatric Psychology. Atlanta, Canada: A ScholarlyEditions ${ }^{\mathrm{TM}}$ eBook.

Baker, S. (1999). Social networks and community resources among older, African American caregivers of people living with HIV/AIDS. J Cult Divers, 6, 124-129. Retrieved from: http://www.questia.com/library/journal/1P3-49067784/social-networks-and-community-resources-among-older.

Bogart, L. M., Cowgill, B.O., Kennedy, D., Ryan, G., Murphy, D.A., Elijah, J., \& Schuster, M.A. (2008). HIV related stigma among people with HIV and their families: a qualitative analysis. AIDS Behav, 12, 244-54. Retrieved from: http://link.springer.com/article/10.1007\%2Fs10461-007-9231-x.

Brouard, P., \& Wills, C. (2006). Washington, DC: POLICY Project/Futures Group. Retrieved from: http://www.policyproject.com/pubs/generalreport/GEN_Internal Stigma.pdf.

Cacioppo, J.T., Hawkley, L.C., Norman, G.J., \& Berntson G. G. (2011). Social Isolation. Ann NY Acad Sci, 1231, 17-22. doi: 10.1111/j.1749-6632.2011.06028.x. Epub 2011 Jun 8.

Cantor, M.H., \& Brennan, M. (20012). Social Care of the Elderly: The Effects of Ethnicity, Class, and Culture. New York, NY: Springer.

Coyle, C. E., \& Dugan, E. (2012). Social isolation, loneliness and health among older adults. J Aging Health, 24(8), 13461363. doi: $10.1177 / 0898264312460275$

Earnshaw, V.A., \& Chaudoir, S.R. (2009). From conceptualizing to measuring HIV stigma: A review of HIV stigma mechanism measures. AIDS Behav, 13(6), 1160-1177. doi:10.1007/s10461-009-9593-3.

Grov, C., Golub, S.A., Parsons, J.T., Brennan, M, \& Karpiak S.E. (2010). Loneliness and HIV-related stigma explain depression among older HIV-positive adults. AIDS Care, 22(5), 630-639. doi:10.1080/09540120903280901.

Hays, R.D., Sherbourne, C.D., \& Mazel, R.M. (1995). User's Manual for Medical Outcomes Study (MOS). Core Measures of health-related quality of life, CA: Santa Monica, RAND Corporation.

Heckman, T.G. (2003). The chronic illness quality of life (CIQOL) model: explaining life satisfaction in people living with HIV disease. Health Psychol, 22,140-7. Retrieved from: http://www.ncbi.nlm.nih.gov/pubmed/12683734.

Hellenic Center for Disease Control \& Prevention [HCDCP]. HIV infection: Latest epidemiological data, October 2017, http://www.keelpno.gr/Portals/0/\%CE\%91\%CF\%81\%CF\%87\%CE\%B5\%CE\%AF\%CE\%B1/HIV/2017/HIV_Greece_Brief \%20epidemiological\%20report_31Oct2017.pdfHerrmann, S., McKinnon, E., Hyland, N.B., Lalanne, C., Mallal, S., Nolan, D., Chassany, O., \& Duracinsky, M. (2013). HIV-related stigma and physical symptoms have a persistent influence on health-related quality of life in Australians with HIV infection. Health Qual Life Outcomes, 11, 56. doi: 10.1186/1477-7525-11-56.

HCDCP E-bulletin. Retrieved at: http://www2.keelpno.gr/blog/?page_id=4448\&lang=en. 
Kalichman, S.C., Simbayi, L., Cloete, A., Mthembu, P.P., Mkhonta, R.N., \& Ginindza, T. (2009). Measuring AIDS Stigmas in People Living with HIV/AIDS: The Internalized AIDS-Related Scake. AIDS Care, 21, 87-93. doi: $10.1080 / 09540120802032627$.

Komatsu, Y., Kai, Y., Nagamatsu, T., Shiwa, T., Suyama, Y., \& Sugimoto, M. (2010). Buffering effect of social support in the workplace on job strain and depressive symptoms. J Occup Health, 52, 140-148. Retrieved from: http://doi.org/10.1539/sangyoeisei.B9012.

Kuper, H., Marmot, M., \& Hemingway, H. (2002). Systematic review of prospective cohort studies of psychosocial factors in the etiology and prognosis of coronary heart disease. Seminars in Vascular Medicine, 2, 267-314.

Lee, R.S., Kochman, A., \& Sikkema, K. J. (2002). Internalized stigma among people living with HIV-AIDS. AIDS Behav, 6(4), 309-319. Retrieved from: http://link.springer.com/article/10.1023\%2FA\%3A1021144511957.

Li, L., Sung-Jae, L., Panithee, T., Chuleeporn J., \& Rotheram-Borus, M.J. (2009). Stigma, social support and depression among people living with HIV in Thailand. AIDS Care, 21, 1007 - 1013. doi: 10.1080/09540120802614358.

Mahajan, A,P., Sayles, J.N., Patel, V.A., Remien, R.H., Sawires, S.R., Ortiz, D.J.,.. Coates, T.J. (2008). Stigma in the HIV/AIDS epidemic: a review of the literature and recommendations for the way forward. AIDS, 22(suppl2), S67S79.doi: 10.1097/01.aids.0000327438.13291.62.

Mills, E. J., Bakanda, C., Birungi, J., Chan, K., Ford, N., Cooper, C. L.,... Hogg, R. S. (2011). Life expectancy of persons receiving combination antiretroviral therapy in low-income countries: a cohort analysis from Uganda. Ann Intern Med, 155(4), 209-216. doi: 10.7326/0003-4819-155-4-201108160-00358.

Mo, P. K. H., \& Coulson, N. S. (2013). Online support group use and psychological health for individuals living with HIV/AIDS. Patient Educ Couns, 93, 426-432. doi: 10.1016/j.pec.2013.04.004.

Nokes, K. M., \& Kendrew, J. (2001). Correlates of sleep quality in persons with HIV Disease. J Assoc Nurses AIDS Care, 12, 17-22. http://dx.doi.org/10.1016/S1055-3290(06)60167-2.

Orrick, E., Worrall, J., Morris, R., \& Wang, X. (2011). Testing social support theory: A multilevel analysis of recidivism. $J$ Crim Justice, 39, 499-508. doi: 10.1016/j.jcrimjus.2011.09.005.

Parpa, E., Pikea, P., Tsilika, E., Galanos, A., Kouloulias, V., Patiraki, E., \& Mystakidou, K. (2016). Psychometric properties of the Medical Outcomes Study in people with HIV and AIDS. IJHSS , 6 (10), 40-46.

Perlman, D., \& Peplau, L. A. (1981). Toward a social psychology of loneliness. In S. W., Duck, S. W., \& Gilmour, R. (Eds). Personal relationships in disorder. London: Academic Press.

Pikea, P., Parpa, E., Tsilika, E., Galanos, A., \& Mystakidou, K. (2016). Psychometric properties of the Greek-UCLA loneliness scale version 3 in a sample of people with HIV. World J AIDS, 6, 157-168.

Russell, D. (1996). UCLA Loneliness Scale (Version 3): Reliability, validity, and factor structure. J Pers Assess, 66, $20-40$. doi: 10.1207/s15327752jpa6601_2.

Sherbourne, C. D., \& Stewart, A. L. (1991). The MOS social support survey. Soc Sci Med, 32(6), 705-14. doi: 10.1016/0277-9536(91)90150-B

Sun, Y.H., Sun, L., Zhang, Z.K., Wang, B., Yu, C., \& Cao, H.Y. (2009). Loneliness, social support and family function of people living with HIV/AIDS in Anhui rural area, China. Int J STD AIDS, 20(4), 255-8. doi: 10.1258/ijsa.2008.008348.

Udell, J. A., Steg, P. G., Scirica, B. M., Smith, S. C. Jr., Ohman, E. M., Eagle, K. A., ... REduction of Atherothrombosis for Continued Health (REACH) Registry Investigators. (2012). Living alone and cardiovascular risk in outpatients at risk of or with atherothrombosis. Arch Intern Med, 23, 172(14), 1086-95.

United Nations Programme on HIV/AIDS (UNAIDS). (2015). World AIDS Day Report. Retrieved from: http://www.unaids.org/en/media/unaids/contentassets/documents/factsheet/2011/20111121_S_WAD2011_global_en.pdf.

United Nations Programme on HIV/AIDS (UNAIDS). (2017). Retrieved from: http://www.unaids.org/en/resources/presscentre/pressreleaseandstatementarchive/2017/november/20171121_rightto health_report.

United Nations Programme on HIV/AIDS (UNAIDS). (2017). Fact sheet - Latest statistics on the status of the AIDS epidemic.

Valtorta, N. K., Kanaan, M., Gilbody, S., Ronzi, S., \& Hanratt, B. (2016). Loneliness and social isolation as risk factors for coronary heart disease and stroke: systematic review and meta-analysis of longitudinal observational studies. Cardiac risk factors and prevention. Heart, 102, 1009-1016.

Van Dam, H.A., Van der Horst, F.G., Knoops, L., Ryckman, R.M., Crebolder, H.F., \& Van den Borne, B.H. (2005). Social support in diabetes: A systematic review of controlled intervention studies. Patient Educ Couns, 59(1), 1-12. Retrieved from: http://dx.doi.org/10.1016/j.pec.2004.11.001.

Ware, N.C., Wyatt, M.A., \& Tugenberg, T. (2006). Social relationships, stigma and adherence to antiretroviral therapy for HIV/AIDS. AIDS Care, 18, 904-10. doi: 10.1080/09540120500330554

World Health Organization. HIV/AIDS, Data and statistics. Retrieved from: http://www.who.int/hiv/data/en/

World Health Organization. (2016). Media Centre, HIV/AIDS, fact sheet Geneva, Switzerland. Retrieved from: http://www.who.int/mediacentre/factsheets/fs360/en/. 